Wright State University

CORE Scholar

Nursing Faculty Publications

Nursing

2-2011

\title{
Parental Perceptions of the Rural School's Role in Addressing Childhood Obesity
}

Ann M. Stalter

Wright State University - Main Campus, ann.stalter@wright.edu

Mary Beth Kaylor

Wright State University - Main Campus, marybeth.kaylor@wright.edu

Jessica D. Steinke

Rosanta M. Barker

Follow this and additional works at: https://corescholar.libraries.wright.edu/nursing_faculty

Part of the Nursing Commons

\section{Repository Citation}

Stalter, A. M., Kaylor, M., Steinke, J. D., \& Barker, R. M. (2011). Parental Perceptions of the Rural School's Role in Addressing Childhood Obesity. The Journal of School Nursing, 27 (1), 70-81.

https://corescholar.libraries.wright.edu/nursing_faculty/249

This Article is brought to you for free and open access by the Nursing at CORE Scholar. It has been accepted for inclusion in Nursing Faculty Publications by an authorized administrator of CORE Scholar. For more information, please contact library-corescholar@wright.edu. 


\title{
Research Article
}

\section{Parental Perceptions of the Rural School's Role in Addressing Childhood Obesity}

\author{
Ann M. Stalter, PhD, RN, Marybeth Kaylor, PhD, RN, Jessica D. Steinke, BSN, RN, and \\ Rosanta M. Barker, BSN, RN
}

This study employed cross-sectional, descriptive design with convenience sampling to explore rural parent perceptions of child obesity, use of Body Mass Index (BMI) in schools, preferences for receipt of BMI information and, the rural school's role in obesity prevention/treatment. The survey "Parental Perceptions of BMI and Obesity in the School-Age Child" was used. Of the 183 surveys distributed, 65 were returned (35.5\%). Fifty-five percentage of parents were in agreement of school-based BMI screening. Fifty-four percentage of parents selected a combination of ways to receive BMI information (letter from school nurse, face-to-face conference with nurse, or via report card). Few parents $(6.2 \%)$ were reluctant to schools addressing obesity. Significant relationships were identified between non-White, overweight parents who had overweight children $(n=3)$. They were more likely to disagree with removal of junk food, increasing physical activity, and recommending weight loss. Recommendations to involve parents in BMI screening are presented.

Keywords: BMI; obesity; screening/risk identification; elementary; quantitative research; community

\section{Background}

In April 2000, the Body Mass Index (BMI) for age and sex was recommended as the screening tool of choice for annual growth monitoring and early identification of unhealthy childhood weight (Centers for Disease Control and Prevention [CDC], 2010). The acceptance of BMI screening in school settings has been controversial. Lack of policy, negative labeling of children, and the role of schools in obesity management has generated debate about the necessity and advantage of implementing school-based BMI screening (Nihizer et al., 2007). Underlying the controversy has been the usefulness and effectiveness of BMI screening in reducing child obesity rates. In essence, the BMI as a "stand alone" benchmark does very little to promote health and prevent disease; it does however have predictive value for development of adult obesity among some populations (Ebbeling, Backstrand, \& Rodriguez, 1999). Increasing awareness of BMI has not promoted or improved health behavior among overweight/obese populations.

Ann M. Stalter, PhD, RN, is an assistant professor in the Wright State University-Miami Valley, College of Nursing and Health, Dayton, OH, USA.

Marybeth Kaylor, PhD, RN, is an assistant professor in the Wright State University-Miami Valley, College of Nursing and Health, Dayton, OH, USA.

Jessica D. Steinke, BSN, RN, is associated with Wright State University-Miami Valley, College of Nursing and Health, Dayton, $\mathrm{OH}, \mathrm{USA}$.

Rosanta M. Barker, BSN, RN, is associated with Wright State University-Miami Valley, College of Nursing and Health, Dayton, $\mathrm{OH}$, USA.

JOSN, Vol. 27 No. 1, February 2011 70-81

DOI: $10.1177 / 1059840510394189$

(C) 2011 The Author(s) 
The usefulness of the BMI is not helpful without information such as activity tracking, dietary history, nutrition knowledge, fluid intake, and family history (Shay, Shobert, Seibert, \& Thomas, 2009). Little research has been done with children in understanding what motivates them to increase activity, eat nutritiously, and manage a healthy weight. Rhee, De Lago, Arscott-Mills, Mehta, and Davis (2005) used Greene et al.'s (1999) Transtheoretical Health Behavior Change Theory (Stages of Change Model) revised for weight reduction to identify parent perceptions of child health behaviors and parent readiness to make lifestyle changes for overweight children. Stages of change range from no interest in changing behavior to maintaining healthy changes as permanent lifestyle. Stage 1, the Pre-contemplation Stage, involves having no interest in health behavior change. According to Rhee (2005), if a parent of an overweight child is pre-contemplative, the parent may be unsupportive of overweight/obesity interventions. Manson, Skerrett, Greenland, and Van Itallie (2004) explained how Prochaska's model works over time

Patients may need to hear a particular message several times before it, or something else in their lives prompts them to action. It also means that a clinician need not consider a message "lost" just because it did not effect an immediate change - it may, indeed, have planted a seed that will sprout later. (Edelman \& Mandle, 2010, p. 256)

This quote reinforces the notion that repetition is an effective strategy for learning (Edelman \& Mandle, 2010).

Changing children's behaviors to increase physical activity, improve eating, and manage weight is a considerable teaching and reinforcement challenge because it involves the parent and the child. Helping a child accurately perceive one's self as overweight or obese has been associated with motivation to change health behavior (Maximova et al., 2008). Youth who are exposed to overweight parents and friends do not perceive themselves as overweight. Thus, readiness and motivation to change behavior are not achieved. Howard (2007) emphasized school-age children at risk for obesity and their parents need assessed for readiness to change health behaviors. The Healthy
Eating and Activity Together (HEAT) guidelines for school age children emphasize a comprehensive family and lifestyle assessment as a routine follow-up care for children with BMIs in the 85th percentiles and above (Gottesman, 2003). Towns and D'Auria's (2009) integrative review of parent perceptions of child overweight identified that parental perceptions of child overweight are influenced by child age, gender, and ethnicity. Further, they found that some parents do not find the BMI and growth charts applicable or meaningful. They underscored that parents need to recognize when their child is overweight and be concerned enough about negative health consequences to take action to improve the situation.

\section{"Changing children's behaviors to increase physical activity, improve eating, and manage weight is a considerable teaching and reinforcement challenge because it involves the parent and the child. Helping a child accurately perceive one's self as overweight or obese has been associated with motivation to change bealth behavior."}

Towns and D'Auria (2009) found that parents of school-age children perceived child overweight/obesity as being in a pivotal time period. Parents viewed school age-children as no longer having time to "outgrow" weight problems (Jain et al., 2001; Rich et al., 2005). Girls were seen as "fatter" than peers, especially by lean mothers (Boutelle, Fulkerson, Neumark-Sztainer, \& Story, 2004; Fisher, Fraser, \& Alexander, 2006; Jeffery, Voss, Metalf, Alba, \& Wilkin, 2005; Maynard, Galuska, Blanck, \& Serdula, 2003). Hispanic children were less likely to be perceived as overweight/ obese by parents (Boutelle et al., 2004). Lower maternal education is associated with an inability to perceive overweight in children after adjusting for a variety of demographic factors. Poverty/low income does not alter parent perception that a child is overweight where the perception is "[we] don't have enough to eat" (Casey, Szeto, Lensing, Bogle, \& Weber, 2001). There is no information about how geography affects parent perception of child overweight. The importance of understanding parent perceptions of child overweight/ obesity is essential to improving child health and 
reducing child overweight/obesity. This is especially true in the context of what is known about the child obesity epidemic in the United States.

To review, child obesity rates among school age populations have recently stabilized (17\%; Institute of Medicine [IOM], 2009). Interrupted only by the Pandemic Flu of 2009, it has been a leading public health priority for over a decade (U.S. Department of Health and Human Services [DHHS], 2000). Among children aged 6 to 11, obesity prevalence increased nearly $7.5 \%$ in 30 years (IOM, 2009). This equates to over 9 million children or nearly $30 \%$ of the U.S child population (Sharma, 2006). Minority children are most at risk for child overweight/obesity with two in five children affected. Hispanic boys aged 6 to 11 $(\sim 30 \%)$ and both black and Hispanic girls aged 6 to $11(\sim 25 \%)$ exceed the prevalence of White non-Hispanic children $(\sim 15 \%)$ of the same age groups (Ludwig, 2007; Ogden, Carroll, Curtin, Lamb, \& Flegal, 2010). It is unclear whether obese minority children are more or less likely to be urban dwellers. The National Advisory Committee on Rural Health and Human Services (NACRHHS, 2005) reports that children residing in U.S. rural areas (population less than 2,000) are at greater risk for obesity than their metropolitan counterparts. Obese rural children over 5 years of age are more likely to be White, uninsured girls, living in poverty with poor access to supermarkets/ food and health care (Lutfiyya, Lipsky, WisdomBehounek, \& Inpanbutr-Martinkus, 2007). Other studies suggest rural living and poor access to food and health care increases the prevalence of obesity in children (Schetzina et al., 2009; Morton \& Blanchard, 2007).

All overweight/obese children are at increased risk for adverse physical health outcomes including adverse blood lipid profile, altered glucose metabolism, and obstructive and sleep apnea. These have the potential to develop into hypertension, diabetes, cardiovascular disease, gallbladder disease, and osteoarthritis in adulthood (Nihizer et al., 2007). Before the Patient Protection and Affordable Care Act (PPACA) was signed into law, the national costs for health care related to obese adults were estimated between $\$ 98$ billion and \$129 billion (Sharma, 2006). These projections were contemporaneous with straining the health care delivery system to have ample available resources to treat the long-term consequences of childhood developed obesity (Duderstadt, 2004). The enactment of PPACA strains the rural family (Center for Rural Affairs, 2010). For example, although PPACA increases coverage to uninsured via taxed income, it does not provide incentives for attracting qualified providers to rural areas (McMorrow, 2010). Parents must assume the responsibility for both paying increased taxes and providing access to routine health screenings. Additionally, parental responsibilities include the provision of highquality food, limiting screen time, and encouraging activity. Other community stakeholders responsible for child health include physicians, teachers, school cafeteria staff, public health educators, nurses, and nutritionists (O'Dea \& Wilson, 2006).

Rural parents' concerns about who shares in the responsibility of early detection and intervention for obesity are not known (Ludwig, 2007). Urban and suburban parent perceptions of routine screenings for obesity in schools have been studied. Findings were ambiguous; some parents favor routine obesity BMI screening in schools and some do not (Nihizer et al., 2007; Murphy \& Polivka, 2007). In essence, some parents view BMI screening as protective and others view it as a barrier to child rearing. School nurses across all geographic areas have been studied and they perceived that rural school environment and parental acceptance were barriers to BMI screening (Moyers, 2005; Stalter, Chaudry, \& Polivka, 2010a). School nurses perceived the rural environment as being a barrier to BMI screening of elementary school children due, in part, to parental acceptance (Stalter, Chaudry, \& Polivka, 2010b).

\section{Purpose}

Exploring rural parents' perceptions may increase understanding in the role of geography in BMI screening in school settings. Understanding rural parental perceptions of the role of the elementary school in collecting BMI information could also enhance the development of knowledge and policy in child obesity. The purpose of this research is to gain an understanding of parental perceptions of an elementary rural school's role in addressing childhood obesity. 
Specific aims The specific aims of this study were to (a) identify parental perceptions regarding the causes of obesity and the use of BMI as a screening tool for obesity in a rural elementary school; (b) identify parental preferences for method of receipt of BMI information in a rural elementary school; (c) identify parental perceptions of the rural school's role in the prevention and treatment of childhood obesity; and (d) identify significant relationships between child overweight and demographic/survey response variables.

\section{Method}

This study is a descriptive, cross-sectional design using survey data.

\section{Survey}

The "Parental Perceptions of Body Mass Index and Obesity in School-Age Children" survey was used in this study with permission (Murphy \& Polivka, 2007). The survey was originally developed by Price, Desmond, Rupport, and Stelzer (1987; Cronbach's alpha, $r=.66$ ), revised by Moyers (2005; Cronbach's alpha, $r=.80$ ), and reused again by Murphy and Polivka (2007; Cronbach's alpha, $r=.80)$. The survey has been used with English-speaking groups. It has a fifth-grade Fleischman-Kinkaid score.

The survey is comprised of 44 items and has two parts. Part One surveys parent perceptions with 30 questions. Parents are asked about familiarity with, usefulness of, and appropriateness of BMI in schools (items 1-3). For the next 5 items (items 4-8), parents use a 5-point Likert-type scale to choose if they strongly agree, agree, are neutral, disagree or strongly disagree with general conclusions about obesity. For example, "Most obese children will outgrow their obesity." The next 10 items (items 9-18) are forced choice, dichotomous variables, where parents are asked whether certain factors play a major role or minor role in causing obesity. For example, "Do you think Heredity/genetics/family traits play a major or minor role in the cause of childhood obesity?"

The next 11 questions (items 19-29) have parents use a 5-point Likert-type scale to choose if they strongly agree, agree, are neutral, disagree or strongly disagree with specific statements about the school's role in preventing and treating childhood obesity. For example, "Schools should offer special low calorie meals." The last question in Part One of the survey (item 30) is multiple choice where parents check their preference for receiving BMI information from schools from a list of seven options. Examples of options include letter from school nurse, face-to-face conference, report card, telephone call from school nurse, and physical education teacher. There is also an openended choice for parents to fill in an answer.

Part Two is a demographic questionnaire and includes 14 questions about both the parent and the child. Questions include parent age, height, weight and child age, height, and weight. The instrument takes about $10 \mathrm{~min}$ to complete.

Sample A convenience sampling method was used, comprising parents with children in a northwestern rural Ohio elementary school. The school was selected because one of the researchers was a previous member of the Parent Teacher Association at the school. It is the smallest unit of measurement, nested in several larger community layers. The school is the only elementary school in the district (statewide $N=1,918$ elementary schools). The school is made up of one building which serves Kindergarteners $(K)$ through sixth graders $(n=183 ; N=810,858)$ and is adjacent to the only other school in the district, the high school. The high school serves 7 th to 12 th graders $(n=297)$. Thus, this school is in a small district within the state (Census.gov, 2010).

The community population is 1,168 . $(N=$ $11,542,645)$. The school draws from a 9 square mile area where 152 families with children under the age of 18 reside. Less than $2 \%$ of families live in poverty and $7.7 \%$ of children are on free or reduced lunches. The median income per household is $\$ 43,000$. The racial makeup of the community is $99.25 \%$ Caucasian and less than $1 \%$ African American, Hispanic and/or other races. Less than $2 \%$ speak another language other than English. Of residents ages $25+, 13.2 \%$ are college educated and $86 \%$ have graduated from high school (Census.gov, 2010).

Inclusion criteria were (a) parents have at least one child between the ages of 4 and 13 years in Grades $\mathrm{K}$ to 6 and (b) parents able to read and write in English. Inclusion criteria for sixth grade 
were considered because age ranges of children were from 11 to 13 . Excluding sixth graders meant a smaller sample size of those children age 11 years.

\section{PROCEDURES}

Approval was obtained from the Wright State University Institutional Review Board and the school superintendent. The questionnaire and a letter explaining the purpose of the study was sent home with every student in the elementary school $(N=183)$. Parents were asked to return the questionnaire within 1 week. No incentives were offered. Anonymous, completed questionnaires were returned to the child's teacher who deposited the completed questionnaires in a manila envelope marked CONFIDENTIAL with the name and address of the researcher on the outside of the envelope. The manila envelope was checked by the researcher biweekly. After 2 weeks, a note was sent home with all students to thank those that completed the questionnaire and to remind those that had not responded. The final response rate was $35.5 \%$. A brief summary of the findings was distributed to the school where the study was performed.

\section{Data Analysis}

Data were entered into PASW Version 18.0 data analysis software. Descriptive statistics and frequency distributions were calculated. The selfreported height and weight data were converted to BMI using an Internet BMI calculator found at the National Heart, Lung and Blood Institute website. BMI data were categorized according to standardized criteria for overweight and obesity (CDC, 2010). Adults with a BMI greater $30 \mathrm{~kg} /$ $\mathrm{m}^{2}$ were considered obese; between 25.1 and $29.9 \mathrm{~kg} / \mathrm{m}^{2}$ were considered overweight; between 17.8 and $25.0 \mathrm{~kg} / \mathrm{m}^{2}$ were considered normal weight; and those adults under $17.8 \mathrm{~kg} / \mathrm{m}^{2}$ were considered underweight.

Children were grouped according to age and gender, BMIs were calculated and then plotted according to age and gender using CDC approved forms for U.S. children. Those with a BMI greater than 95 th percentile $(28.1 \mathrm{~kg} / \mathrm{m} 2)$ were considered obese; between 85 th and 95 th percentiles $\left(25.1-28 \mathrm{~kg} / \mathrm{m}^{2}\right)$ were considered overweight;

\begin{tabular}{lc} 
TABLE 1. Characteristics of the Parent Participants \\
\hline Characteristic of Adults \\
\hline Age in years $(N=64)$ & $N(\%)$ \\
$20-30$ & $6(9.2)$ \\
$31-40$ & $39(60)$ \\
$41-50$ & $18(27.7)$ \\
$51-60$ & $1(1.5)$ \\
Race $(N=64)$ & \\
White & $62(95.4)$ \\
Black & $1(1.5)$ \\
Asian & $1(1.5)$ \\
Latino & 0 \\
Other & 0 \\
Education level $(N=64)$ & \\
Less than high school & 0 \\
High school or equivalent & $16(24.6)$ \\
Some college & $8(12.3)$ \\
College graduate & $40(61.5)$ \\
Body Mass Index $(N=57)$ & \\
$17.8-25.0$ (normal) & $29(44.6)$ \\
25.1-29.9 (overweight) & $15(23.1)$ \\
$\geq 30.0$ (obese) & $13(20.0)$
\end{tabular}

between 5 th and 84 th percentiles $\left(18.1-24.9 \mathrm{~kg} / \mathrm{m}^{2}\right)$ were considered normal weight; and those below the 5 th percentile (under $18.0 \mathrm{~kg} / \mathrm{m}^{2}$ ) were considered underweight. Two-sided chi-square testing was performed to determine associations between child overweight status demographic/survey response variables using a $p=.05$ level of significance.

\section{RESULTS}

\section{Respondents}

Parents completing the survey generally were female, White, and 3--40 years old; , had two schoolage children; and were college graduates with a BMI between 18.8 and $62.7 \mathrm{~kg} / \mathrm{m}^{2}\left(M=26.64 \mathrm{~kg} / \mathrm{m}^{2}\right.$; $S D=6.87$; Table 1$)$. The typical child described by the parent was between 7 and 8 years old, White, female, and had a BMI between 10.0 and $34.2 .9 \mathrm{~kg} / \mathrm{m}^{2}\left(M=18.33 \mathrm{~kg} / \mathrm{m}^{2} ; S D=4.07\right.$; Table 2).

\section{Parental Perceptions of the Causes of Obesity and the Efficacy of BMI}

In this study, $95.4 \%$ of parents were familiar with BMI. In addition, $80 \%$ of the parents found BMI to be very or somewhat useful in providing information about their child's weight. About 55\% strongly 
TABLE 2. Characteristics of the Children as Described by the Parents Surveyed

\begin{tabular}{|c|c|c|c|c|c|c|c|c|c|}
\hline Characteristic & $n(\%)$ & Characteristic & $n(\%)$ & Characteristic & $n(\%)$ & Characteristic & $n(\%)$ & Characteristic & $n(\%)$ \\
\hline Age $(N=65)$ & & Grade $(N=64)$ & & $\begin{array}{l}\text { Race } \\
\qquad(N=65)\end{array}$ & & $\begin{array}{l}\text { Gender } \\
\qquad(N=65)\end{array}$ & & $\begin{array}{l}\text { Body Mass Index } \\
\quad(N=59)\end{array}$ & \\
\hline 5-6 years & $12(18.5)$ & $\begin{array}{l}\text { Pre-school or } \\
\text { kindergarten }\end{array}$ & $13(20.0)$ & White & $61(93.8)$ & Boys & $31(47.7)$ & $\begin{array}{l}<18.0 \\
\quad \text { (underweight) }\end{array}$ & $31(47.7)$ \\
\hline $7-8$ years & $27(41.5)$ & $1 \mathrm{st}$ & $15(23.3)$ & Black & $3(4.6)$ & Girls & $34(52.3)$ & $18.1-24.9$ (normal) & $25(38.5)$ \\
\hline $9-10$ years & $15(23.1)$ & 2nd & $11(16.9)$ & Asian & $1(1.5)$ & & & $\begin{array}{l}25.1-28.0 \\
\quad \text { (overweight) }\end{array}$ & $2(3.1)$ \\
\hline \multirow[t]{4}{*}{$11+$ years } & $10(15.4)$ & $3 \mathrm{rd}$ & $6(9.2)$ & Other/mixed & $0(0)$ & & & $\geq 28.1$ (obese) & $1(1.5)$ \\
\hline & & 4 th & $10(15.4)$ & & & & & Missing $^{\mathrm{a}}$ & $6(10)$ \\
\hline & & $5^{\text {th }}+$ & $9(15.2)$ & & & & & & \\
\hline & & Missing $^{a}$ & $1(1.5)$ & & & & & & \\
\hline
\end{tabular}

Note: ${ }^{a}$ Missing data are because parent did not fill in the information.

TABLE 3. Parents' Perceptions of Childhood Obesity $(n=65)$

\begin{tabular}{lccc}
\hline & Strongly Agree/Agree & Neutral & Disagree/Strongly Disagree \\
\hline Normal weight is important to the health of children & $64(98.9)$ & 0 & $1(1.5)$ \\
Childhood obesity is becoming more common & $61(93.8$ & $4(6.2)$ & 0 \\
Most obese children will outgrow their obesity & $4(6.2)$ & $16(24.6)$ & $45(69.2)$ \\
Reducing childhood obesity is easier than reducing obesity in adulthood & $44(67.7)$ & $16(24.6)$ & $5(7.7)$ \\
Childhood obesity is a significant cause of peer rejection & $50(76.9)$ & $11(16.9)$ & $4(6.2)$ \\
\hline
\end{tabular}

TABLE 4. Parents Perception of Cause of Obesity $(n=65)$

\begin{tabular}{lcc}
\hline & $\begin{array}{c}\text { Major } \\
\text { Role }\end{array}$ & $\begin{array}{c}\text { Minor } \\
\text { Role }\end{array}$ \\
\hline Poor eating behavior & $63(96.9)$ & $2(3.1)$ \\
Excessive caloric intake & $63(96.9)$ & $2(3.1)$ \\
Inactivity (video games/TV/computer & $63(96.9)$ & $2(3.1)$ \\
$\quad$ time) & $29(44.6)$ & $36(55.4)$ \\
Heredity/genetics/family traits & $21(32.3)$ & $44(67.7)$ \\
Cultural factors & $38(58.5)$ & $26(40.0)$ \\
"Junk food machines" & $52(80.0)$ & $12(18.8)$ \\
Lack of parental control $(n=64)$ & $18(27.7)$ & $46(70.8)$ \\
Low socioeconomic class $(n=64)$ & $23(35.4)$ & $42(64.6)$ \\
Peer pressure & $20(30.8)$ & $44(67.7)$ \\
Hormone problems $(n=64)$ & & \\
\hline
\end{tabular}

agreed or agreed that BMI is appropriate for schools to use in weight screening, while $7 \%$ thought it was inappropriate. Parents were asked to respond to 5 items regarding the seriousness of childhood obesity. Respondents reported that normal weight is important to the health of children $(98.9 \%)$, childhood obesity is becoming more common (93.8\%), reducing childhood obesity is easier than reducing obesity in adulthood (67.7\%), and most obese children will not outgrow their obesity (69.2\%; Table 3$)$. To determine parental perceptions of the causes of childhood obesity, parents decided whether
10 items had a major or minor role in obesity development. The majority of parents reported that poor eating behaviors $(96.9 \%)$, excessive caloric intake $(96.9 \%)$, inactivity $(96.9 \%)$, and lack of parental control $(80 \%)$ had major roles in childhood obesity development. Other items such as cultural factors, peer pressure, hormone, or hereditary traits did have a major role in obesity among respondents (Table 4).

\section{Parental Preference for the Receipt of BMI Information}

In order to determine how they would like to receive their child's BMI information from the school, parents were given seven options including "other" and if schools should have a role in collecting BMI information or addressing obesity. Approximately $54 \%$ of parents selected a combination of ways to receive information from the school including a letter from the school nurse, a face-to-face conference with the school nurse, and information included with the report card. About $6 \%$ of parents responded that schools should not address the issue of overweight or obesity. Those selecting "other" were given the opportunity to 


\begin{tabular}{|c|c|c|c|}
\hline & $\begin{array}{c}\text { Strongly } \\
\text { Agreel } \\
\text { Agree }\end{array}$ & Neutral & $\begin{array}{c}\text { Disagree/ } \\
\text { Strongly } \\
\text { Disagree }\end{array}$ \\
\hline Schools are not doing enough to alleviate childhood obesity & $21(32.3)$ & $33(50.8)$ & $11(16.9)$ \\
\hline $\begin{array}{l}\text { A comprehensive health curriculum with units on nutrition and weight control should be available in } \\
\text { every school }\end{array}$ & $34(52.3)$ & $26(40.0)$ & $5(7.7)$ \\
\hline Schools should eliminate the "junk food" machines & $50(76.9)$ & $11(16.9)$ & $4(6.2)$ \\
\hline Schools should offer special low calorie meals & $27(41.5)$ & $2(38.5)$ & $13(20)$ \\
\hline Schools should offer on-site weight control treatment programs for students & $22(33.8)$ & $26(40.0)$ & $17(26.2)$ \\
\hline Physical education classes especially for overweight children should be available in every school & $37(56.9)$ & $14(21.5)$ & $14(21.5)$ \\
\hline Schools should recommend treatment for weight loss for all children who are obese & $24(36.9)$ & $23(35.4)$ & $18(27.7)$ \\
\hline Schools are obligated to counsel the parents of obese children concerning the health risk of obesity & $21(32.3)$ & $23(35.3)$ & $21(32.3)$ \\
\hline $\begin{array}{l}\text { Schools should recommend treatment for weight loss only for children (or parents of children) who ask } \\
\text { for help }\end{array}$ & $32(49.2)$ & $17(26.2)$ & $16(24.6)$ \\
\hline $\begin{array}{l}\text { Schools should recommend treatment for weight loss only for children with a health problem affected by } \\
\text { their obesity }\end{array}$ & $12(18.5)$ & $21(32.3)$ & $32(49.2)$ \\
\hline Schools should not recommend treatment for weight loss $(n=64)$ & $15(23.4)$ & $25(39.1)$ & $24(37.5)$ \\
\hline
\end{tabular}

provide opinion about additional ways to receive BMI information. Generally, parents who selected this option did not provide an alternative method. Rather, they elaborated on their selection of the listed choices. Some of the comments received from parents in regards to "other" alternatives included leaving the issue of student BMI to pediatricians and family physicians rather than it being addressed by schools. A suggestion for more parental education about BMI and weight control from the school was also offered.

\section{Parental Perceptions of the School's Role}

Nearly half (50.8\%) of the parents had a neutral opinion of whether schools were doing enough to alleviate childhood obesity and agreed or strongly agreed that a comprehensive health curriculum with units on nutrition and weight control should be available in every school. Another $40 \%$ had a neutral opinion on the topic of health curriculum related to obesity. Parents noted that physical education classes should be available for all children in school (56.9\%), and they generally supported eliminating junk food machines from schools (76.9\%). About half (49.2\%) of parents agreed that schools should recommend treatment for weight loss only for children or parents of children who ask for help. Parents (49.2\%) disagreed or strongly disagreed that schools should recommend treatment for weight loss only for children with a health problem affected by obesity. Nearly $37 \%$ of parents agreed or strongly agreed that schools should recommend treatment for weight loss for all children that are obese (Table 5).

\section{Significant Relationships Between Child Overweight and Demographic/Survey Response Variables}

There was no significant association between demographic variables (child age, grade, or parent education) if the child was overweight or obese $(n=3)$. There was a significant association between the child's weight and race if the child weight and race where non-White children were more likely to be overweight or obese $\left(\chi^{2}[4, N=65]=8.68\right.$, $p=.013)$. The weight of the adult was significantly associated with if the child was overweight or obese $\left(\chi^{2}[28, N=65]=55.00, p=.002\right)$. The race of the adult (non-White) was significantly associated with if the child was overweight or obese $\left(\chi^{2}[2, N=65]=18.681, p=.000\right)$.

There were no significant associations between parent familiarity with BMI, parent perception of BMI usefulness, and/ parent perception of BMI appropriateness and child overweight status. There was a significant association between the child overweight status or obesity status and parent disagreement with elimination of "junk food" (item $21 ;\left(\chi^{2}[4, N=65]=9.91 ; p=.42\right)$. There was a significant association between the child overweight or obesity status and parent disagreement that additional physical education classes for overweight children should be available in every school (item $24 ;\left(\chi^{2}[4, N=65]=10.12 ; p=.038\right)$. Finally, 
there was a significant association between the child overweight or obesity status and parent disagreement that schools should recommend treatment for weight loss for all children who are obese (item $26 ;\left(\chi^{2}[4, N=65]=20.83 ; p=.001\right)$.

\section{DISCUSSION}

This study was a replication of Murphy and Polivka's (2007) study. Murphy and Polivka's study explored parental perceptions related to childhood obesity in suburban schools and appropriateness of BMI as a screening tool. This study focused on parents from rural schools and investigated rural parents' perceptions of what role the school should have and the preferred method for BMI information distribution.

Parents in this study identified that the leading causes of childhood obesity are inactivity from video games, television, and computer time; excessive caloric intake; poor eating behaviors; and lack of parental control. These results were supported by Murphy and Polivka (2007) who found that $96.6 \%$ of the parents' surveyed felt poor eating behavior had a major role in development of childhood obesity. Because of the survey design and item selection, we recognized there is a general lack of knowledge about whether poor eating is related to supervised or unsupervised food selection, food availability, or other reasons. The majority of the parents in this study was familiar with BMI and felt that BMI was useful in providing information about children's weight. The fact that parents felt less strongly that BMI was appropriate for schools to use in weight screening may indicate a geographic-related difference, as Harris and Neal (2009) identified that rural parent perceptions of school-based BMI screenings were generally less positive because parents were generally less accepting of school-based BMI screening programs.

\footnotetext{
"Parents in this study identified that the leading causes of childhood obesity are inactivity from video games, television, and computer time; excessive caloric intake; poor eating behaviors; and lack of parental control."
}

Murphy and Polivka found that over $75 \%$ of suburban parents felt schools should address overweight or obesity. In contrast, we found $93.8 \%$ of rural parents felt schools should address overweight or obesity. Over half of parents in this study (54\%) preferred to receive their child's BMI information in a letter from the school nurse, face-to-face conference with the nurse, in child's report card, or combination of these. Murphy and Polivka found that suburban parents preferred to receive BMI information in a letter from the nurse. In a qualitative study that employed focus groups to explore parental perceptions of rural schools in West Virginia, parents conveyed a strong preference for health-related information be mailed directly to the home and were reluctant to have schools managing obesity without parental consent. They voiced concerns about having control over who, how, and when BMI data would be gathered (Harris \& Neal, 2009).

Just as in Murphy and Polivka's study, parents in this study were fairly neutral regarding whether schools are doing enough to alleviate childhood obesity. Previous studies identified that schools were not doing enough to alleviate childhood obesity, a barrier that Murphy and Polivka related as lessening because of parental awareness and concern for child obesity (Moyers, 2005; Nihizer, 2007). Respondents in this study strongly supported a comprehensive health curriculum with units on nutrition and weight control, as well as, eliminating "junk food" machines from schools. These points were also supported in the Murphy and Polivka study. Since this study was designed, Ohio passed a law that schools can no longer provide junk food in vending machines. In fact, children (kindergarteners through sixth graders) are not permitted to buy snacks that exceed 150 calories. And, regardless of grade level, fat content of foods and snacks available in Ohio schools must not exceed $35 \%$ of total calories. Further, sugar content of foods and snacks available in Ohio schools cannot exceed $35 \%$ by total weight and transfat is banned (Bischoff, 2009).

Generally parents from this study, as well as, Murphy and Polivka's study were neutral regarding whether schools should recommend treatment for weight loss for all obese children or if schools are obligated to counsel the parents of obese children. In contrast, rural parents studied by Harris and Neal (2009) were of the opinion that if rural 
schools assessed a child's BMI and identified a health concern, that the school was obligated to intervene at least with a referral and information to help parents resolve the issue.

The chi-square results are noteworthy in that overweight and obese children in this study were more likely to be non-White, which is consistent with national findings (Ogden et al., 2010). On the contrary, findings from this study were not consistent with other studies involving rural settings and using smaller than national sized samples (Harris \& Neal, 2009; Lutfiyya et al., 2007). It is also worth mentioning that parents of overweight or obese children were more likely to disagree with elimination of junk food, additional school-based physical activity requirements, and school-based weight loss intervention. Findings that parents of obese children not planning to eliminate junk food, promote physical activity, or implement weight loss interventions are reflective of poor health behaviors, which consequentially result in and perpetuate altered health status (Edelman \& Mandle, 2010). The findings reinforce Rhee's (2005) and Maximova's (2008) studies that identified parents with overweight children not ready for change and being in the Pre-contemplative Stage of Prochaska's model.

There was a significant relationship between overweight/obese adult status and overweight/ obese child status as well as non-White adult race and overweight/obese child status. These findings are also consistent national data, regardless of rural setting. Fitzgibbon and Beech (2009) offer rationale for why overweight/obese minority parents have varied perceptions of obesity. They assert the way in which information on child BMI is presented and received by parents must be considered in a cultural context by developing culturally sensitive BMI notification programs specifically for minority parents. In other words, to maximize BMI screening effectiveness, target minority overweight parents with materials congruent with social and cultural values, traditions, and practices.

The sample was comprised mostly of college educated parents, therefore the lack of a significant relationship between parent education and weight status is not surprising. The sample is not representative of most communities or schools. In fact, most rural communities have higher than average high school dropout rates (Maurer \& Smith, 2009).

\section{Limitations of the Study}

This descriptive study of perceptions of childhood obesity has several limitations. Self-report bias is a concern as height and weight were reported by parents for themselves and their child. Because the survey was sent home with students, the researchers did not have direct contact with the participants, which could have contributed to the low response rate. Other reasons for a low response rate could include a lack of incentive for participation, a lack of interest in the topic, or to an increasing acceptance of BMI resulting in a parental decision to ignore the survey.

The major limitation of this study was that it was not a representative sample of rural parents in the nation; it was limited to a convenience sample of parents of school-age children from one rural school. Sampling of a single school provides a very limited view of rural schools so the sample was not representative of all rural areas. Therefore, the parent perceptions in this study may not be representative of other rural parents living in non-midwestern regions of the United States.

Results must also be interpreted with caution due to fact that there were very few overweight/ obese children in the study $(n=3)$. This small number is not consistent with nationally calculated rates. This small number must also be considered when applying the findings from the chi-square analyses. Additionally, the number of college educated parents is also not consistent with national rates.

\section{IMPLICATIONS FOR SCHOOL NURSING PRACTICE}

Parents in this study reported they wanted to know their child's BMI and are open to receiving the information in variety of ways including a letter from the school nurse. The impact of providing school-based BMI results is unknown. The importance of understanding parent opinion is timely, given recent state legislations requiring $\mathrm{BMI}$ assessment for children at school entry, third, fifth, and ninth grades. Because in some cases, the law allows school districts to opt out of BMI screenings and allows parents to decline BMI screening for their children, school nurses need to know how to educate and inform both school 
officials and parents on the need for annual BMI screening. In Ohio, legislation also requires that a council of experts make recommendations to the state department of education related to best practices in physical activity, nutrition, and BMI screenings (Ohio Association of School Nurses [OASN], 2010). As school nurses plan to have representation on such councils, it is important that representatives understand the unique perceptions of parents, especially rural parents because current research suggests their opinions may be different than other geographic counterparts (Stalter et al., 2010b). This study suggests overweight minority parents living in a rural setting may have unique perceptions.

It important for school nurses to be systematic in screening and adhere to research-based national guidelines in obtaining, reporting, informing, referring, and following up on BMI screening data (King, Meadows, Engelke, \& Swanson, 2006). An important consideration to BMI legislation requiring collection of crosssectional data is BMI does not give an accurate depiction of changes in BMI over time (Speroni et al., 2007). It is suggested that schools establish databases to collect and analyze longitudinal BMI data, which coincide with data collection on food, physical activity, school environment, and parent/child readiness to implement healthy lifestyle behaviors. Finally, actively integrating primary prevention through health promotion and disease prevention that address the unique needs of the rural population are essential for longterm community participation and acceptance of school-based BMI screening and intervention programming (King et al., 2006). This may involve developing culturally sensitive materials with respect to health literacy issues (Fitzgibbon \& Beech, 2009; McCray, 2005). It may also involve confrontation when dealing with parents who are not ready to adopt healthy weight management behaviors (Mikhailovich \& Morrison, 2007).

At this time, based on information received from the parent surveys, it is recommended that school nurses, especially those working in rural settings who are planning to implement sending letters home to parents regarding their child's weight should do so after coordinated planning with school administrators (Nihizer, 2007). A protocol should be developed and approved by the appropriate school administrative boards.
The protocol should include a standardized letter informing parents of their BMI. The protocol should initially be piloted to assess response and ease transition. Prior to implementation, appropriate counseling and referral systems need to be in place for both the parent and the child. Outcomes in terms of impact on the child's BMI and parental compliance should be determined. If possible, collaboration with primary care providers should take place in order to ensure consistent messages are being delivered to the parent and child (Nihizer, 2007).

"At this time, based on information received from the parent surveys, it is recommended that school nurses, especially those working in rural settings who are planning to implement sending letters bome to parents regarding their child's weight should do so after coordinated planning with school administrators."

As school nurses strive to promote health through evidence-based practice, those working in rural settings should be aware that reluctance has been a common theme in terms of parental acceptance of schools managing obesity. The findings from this study did not determine that parents of children in rural schools were reluctant to receive information about BMI. It was found that most parents in this study supported school involvement of children afflicted with obesity. This study provided insight into why some rural parents might be reluctant or disagreeable to junk food elimination, increasing physical activity requirements, and/or weight loss interventions. Lastly, it is encouraging that as childhood obesity is a growing concern, rural parents recognize that normal weight is important to the health of children and that rural children are at more risk for unhealthy weight. School nurses are in key positions to determine rural parent preferences and beliefs about BMI screening and obesity management in their school district. This can be done by collecting information through multiple routes including e-mail survey and oral surveys from the entire district. Annual collection and analysis of BMI data could prove to be very beneficial in identifying trends in rural children. Analysis of dietary and physical activity trends in the school setting could also 
provide insight into weight trends of rural students. Gathering such data can help school nurses to better implement programs and utilize resources within the rural schools to fight childhood obesity.

\section{REFERENCES}

Bischoff, L. (2009, December 16). School ban on junk food heads to Ohio Senate. Dayton Daily News. Retrieved from http://www.daytondailynews.com/news/ohio-news/school-ban-on-junk-food-headsto-ohio-senate-452301.html

Boutelle, K., Fulkerson, J. A., Neumark-Sztainer, D., \& Story, M. (2004). Mothers' perceptions of their adolescents' weight status: Are they accurate. Obesity Research, 12, 1754-1757.

Casey, P. H., Szeto, K., Lensing, S., Bogle, M., \& Weber, J. (2001). Children in food insufficient, low-income families. Prevalence, health and nutrition status. Archives of Pediatrics and Adolescent Medicine, 155, 508-514.

Center for Rural Affairs. (2010). Retrieved from http://www.raconline. org/info_guides/obesity/

Centers for Disease Control and Prevention. (2010). Retrieved from http://www.cdc.gov/obesity/childhood/index.html

Census.gov. (2010). Americanfactfinder/.

Duderstadt, K. G. (2004). Advocacy for reducing childhood obesity. Journal of Pediatric Health Care, 18, 103-105.

Ebbeling, C. B., Backstrand, J. R., \& Rodriguez, N. R. (1999). Screening indices for pediatric obesity. Nutrition Research, 19, 805-815.

Edelman, C., \& Mandle, C. (2010). Health promotion throughout the lifespan (7th ed.). St. Louis, MO: Mosby Elsevier.

Fisher, L., Fraser, J., \& Alexander, C. (2006). Caregivers' inability to identify childhood adiposity: A cross-sectional survey of rural children and their caregivers' attitudes. Australian Journal of Rural Health, 14, 56-61.

Fitzgibbon, M. L., \& Beech, B. M. (2009). The role of culture in the context of school-based BMI screening. Pediatrics, 124, S50-S62. doi:10.1542/peds.2008-3586H.

Gottesman, M. M. (2003). Healthy Eating and Activity Together (HEAT): Weapons against obesity. Journal of Pediatric Health Care, 17, 210-215.

Greene, G. W., Rossi, S. R., Rossi, J. S., Velicer, W. F., Fava, J. L., \& Prochaska, J. O. (1999). Dietary applications of the stages of change model. Journal of American Dietetic Association, 99, 673-678.

Harris, C. V., \& Neal, W. E. (2009). Assessing BMI in West Virginia schools: Parent perspectives and the influence of context. Pediatric, 124, S63-S72.

Howard, K. (2007). Childhood overweight: Parental perceptions and readiness for change. Journal of School Nursing, 23, 73-79. doi:10.1177/10598405070230020301.

Institute of Medicine. (2009). Study designs and analytic strategies for environmental and policy research on obesity, physical activity, and diet by Sallis, JF, Story, M.,\& Lou, D. American Journal of Preventative Medicine, 36, S72-S77. doi:10.1016/j.amepre. 2008.10.006

Jain, A., Sherman, S. N., Chamberlin, L. A., Carter, Y., Powers, S.W., \& Whitaker, R. C. (2001). Why don't low-income mothers worry about their preschoolers being overweight. Pediatrics, 10, 1138-1146.

Jeffery, A. N., Voss, L. D., Metalf, B. S., Alba, S., \& Wilkin, T. J. (2005). Parents' awareness of overweight in themselves and their children: Cross sectional study with a cohort (EarlyBird 21). British Medical Journal, 330, 23-24.
King, C., Meadows, B., Engelke, M. K., \& Swanson, M. (2006). Prevalence of elevated body mass index and blood pressure in a rural school-aged population: Implications for school nurses. Journal of School Health, 76, 145-149.

Ludwig, D. S. (2007). Childhood obesity-the shape of things to come. New England Journal of Medicine, 357, 2325-2327.

Lutfiyya, M. N., Lipsky, M. S., Wisdom-Behounek, J., \& InpanbutrMartinkus, M. (2007). Is rural residency a risk factor for overweight and obesity for U.S. children? Obesity, 15, 2348-2356.

Manson, J. E., Skerrett, P. J., Greenland, P., \& VanItallie, T.B. (2004). The escalating pandemics of obesity and sedentary lifestyle. A call to action for clinicians. Archives of Internal Medicine, 164, 249-253.

Maurer, F., \& Smith, C. (2009). Community/Public bealth nursing practice: Health for families and populations (4th ed.). Philadelphia, PA: Elsevier Saunders.

Maximova, K., McGrath, J., Barnett, T., O'Loughlin, J., Paradis, G., \& Lambert, M. (2008). Do you see what I see? Weight status misperception and exposure to obesity among children and adolescents. International Journal of Obesity, 32, 1008-1015.

Maynard, L. M., Galuska, D. A., Blanck, H. M., \& Serdula, M. K. (2003). Maternal perceptions of weight status of children. Pediatrics, 111, 1226-1231.

McCray, A. T. (2005). Promoting health literacy. Journal of the American Medical Informatics Association, 12, 152-163.

Mikhailovich, K., \& Morrison, P. (2007). Discussing childhood overweight and obesity with parents: a health communication dilemma. Journal of Child Health Care, 11, 311-322. doi:10.1177/ 1367493507082757

McMorrow, S. (2010). Will the patient protection and affordable care act of 2010 improve health outcomes for individuals and families? Timely analysis of immediate health policies. Retrieved on October 16, 2010, from http://www.urban.org/expert.cfm? ID $=$ StaceyMcMorrow

Murphy, M., \& Polivka, B. (2007). Parental perceptions of the school's role in addressing childhood obesity. The Journal of School Nursing, 23, 40-46.

Moyers., Bugle L., \& Jackson, E. (2005). Perceptions of school nurses in school-age children. The Journal of School Nursing, 21, 86-93.

National Advisory Committee on Rural Health and Human Services. (2005). The 2005 Report to the secretary: Rural health and human service issues. Retrieved on October 15, 2010, $\mathrm{ftp}: / / \mathrm{ftp}$.hrsa.gov/ruralhealth/NAC2005.pdf

Nihizer, A. J., Lee, L. M., Wechsler, H., McKenna, M., Odom, E., Reinhold, C., ... Grummer-Strawn, L. (2007). Body mass index measurement in schools. Journal of School Health, 77, 651-671.

O'Dea, J. A., \& Wilson, R. (2006). Socio-cognitive and nutritional factors associated with body mass index in children and adolescents: Possibilities for childhood obesity prevention. Health Education Research, 21, 796-805.

Ogden, C. L., Carroll, M. D., Curtin, L. R., Lamb, M. M., \& Flegal, K. M. (2010). Prevalence of high body mass index in U.S. children and adolescents, 2007-2008. Journal of American Medical Association, 303, 242-249.

Ohio Association of School Nurses. (2010). Ohio Association School Nurse Alert. Updated: Amended Sub SB 210 - Healthy Choices for Healthy Children Legislation.

Price, J., Desmond, S., Rupport, E., \& Stelzer, C. (1987). School nurses' perceptions of childhood obesity. Journal of School Health, 57, 332-336.

Rhee, K. E., De Lago, C. W., Arscott-Mills, T., Mehta, S. D., \& Davis, R. K. (2005). Factors associated with parental readiness to make changes for overweight children. Pediatrics, 116, e94-e101. 
Rich, S. S., DiMarco, N. M., Huettig, C., Essery, E. V., Andersson, E., \& Sanborn, C. F. (2005). Perceptions of health status and play activities in parents of overweight Hispanic toddlers and preschoolers. Family Community Health, 28, 130-141.

Schetzina, K. E., Dalton, W. T., Lowe, E. F., Azzazy, N., Von Werssowetz, K. M., Givens, C., ... Stern, H. P. (2009). A coordinated school health approach to obesity prevention among Appalachian youth: The winning with wellness pilot project. Family and Community Health, 32, 271-285.

Sharma, M. (2006). School-based interventions for childhood and adolescent obesity. The International Association for the Study of Obesity, 7, 261-269.

Shay, L., Shobert, J., Seibert, D., \& Thomas, L. (2009). Adult weight management: Translating research and guidelines into practice. Journal of the American Academy of Nurse Practitioners, 21, 197-206. doi:10.1111/j.1745-7599.2008.00383.x

Speroni, K. G., Tea, C., Earley, C., Niehoff, V., \& Atherton, M. (2007). A pilot community program implementing fitness and lifestyle changes to decrease childhood obesity in children with body mass index of $>85$ percentile. Bariatric Nursing and Surgical Patient Care, 2, 255-265.
Stalter, A. M. (2009). Assessing facilitating factors and barriers to body mass index screening among school nurses (Doctoral dissertation). Retrieved from http://rave.ohiolink.edu/etdc/view?acc_num= osu236626402

Stalter, A. M., Chaudry, R. V., \& Polivka, B. J., (2010a, August). Facilitating factors and barriers to BMI screening in schools. The Journal of School Nursing. 28(4). 320-330. doi:10.1177/ 0123456789123456

Stalter, A. M., Chaudry, R. V., \& Polivka, B. J. (2010b). Regional differences as barriers to body mass index screening described by Ohio school nurses. Journal of School Health. Accepted for publication

Towns, N., \& D'Auria, J. (2009). Parental perceptions of their child's overweight: An integrative review of literature. Journal of Pediatric Nursing. April, 24, 115-130.

U.S. Department of Health and Human Services. (2000). Healthy People 2010. Boston, MA: Jones \& Bartlett. Retrieved from http://www.healthypeople.gov/document/

Morton, L. W., \& Blanchard, T. (2007, February). Starved for access: Life in rural America's food deserts. Rural Realities. Rural Sociological Society. Retrieved from http://www.ruralsociology.org/pubs/ RuralRealities/Issue4.html

For reprints and permissions queries, please visit SAGE's Web site at http://www.sagepub.com/journalsPermissions.nav 